
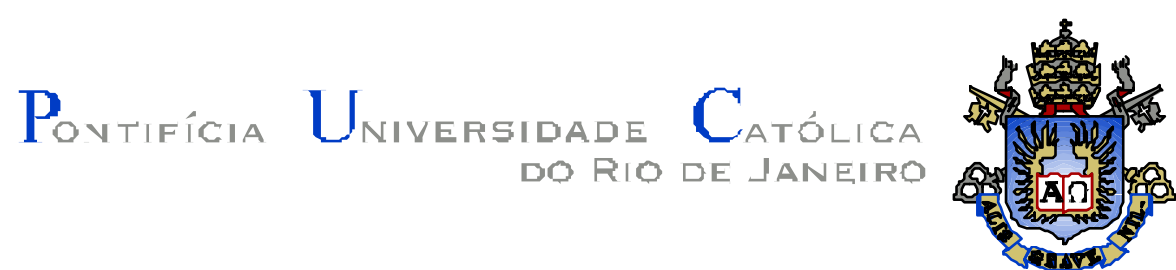

Ana Beatriz Favero

\title{
A noção de trauma em psicanálise
}

\section{TESE DE DOUTORADO}

\section{DEPARTAMENTO DE PSICOLOGIA \\ Programa de Pós-Graduação \\ em Psicologia Clínica}




\section{Povtificia U Uiversidade $C_{\text {atólica }}$ DO RIO DE JANEIRO}

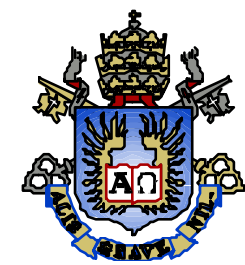

Ana Beatriz Favero

\section{A noção de trauma em psicanálise}

\section{Tese de Doutorado}

Tese apresentada ao Programa de Pós-Graduação em Psicologia Clínica do Departamento de Psicologia da PUC-Rio como parte dos requisitos parciais para obtenção do título de Doutor em Psicologia Clínica.

Orientadora: Prof. ${ }^{\text {a }}$ Ana Maria Rudge

Rio de Janeiro

Março de 2009 


\title{
Ana Beatriz Favero
}

\section{A noção de trauma em psicanálise}

Tese apresentada como requisito parcial para obtenção do grau de Doutor pelo Programa de Pós-Graduação em Psicologia Clínica do Departamento de Psicologia do Centro de Teologia e Ciências Humanas da PUC-Rio. Aprovada pela Comissão Examinadora abaixo assinada.

\author{
Profa. Ana Maria Rudge \\ Orientadora \\ Departamento de Psicologia - PUC-Rio \\ Profa. Maria Teresa da Silveira Pinheiro \\ Instituto de Psicologia - UFRJ \\ Profá. Tânia Coelho dos Santos \\ Instituto de Psicologia - UFRJ \\ Profo. Marco Antonio Coutinho Jorge \\ Instituto de Psicologia - UERJ \\ Profo. Márcio Orlando Seligmann-Silva \\ Departamento de Teoria Literária - Unicamp
}

Prof. Paulo Fernando Carneiro de Andrade Coordenador Setorial de Pós-Graduação e Pesquisa do Centro de Teologia e Ciências Humanas - PUC-Rio

Rio de Janeiro, 1200 
Todos os direitos reservados. É proibida a reprodução total ou parcial do trabalho sem autorização da universidade, da autora e da orientadora.

\section{Ana Beatriz Favero}

Mestre em Psicologia Clínica pela Pontifícia Universidade Católica do Rio de Janeiro (PUC-Rio). Estudou no Instituto de Psicologia da Universidade Federal do Rio de Janeiro (UFRJ), graduando-se pelos cursos de Bacharelado em Psicologia e Formação de Psicólogo em 1994. Cursou Licenciatura em Psicologia pela Faculdade de Educação da UFRJ em 1994/95.

Ficha Catalográfica

Favero, Ana Beatriz

A noção de trauma em psicanálise / Ana Beatriz Favero; orientadora: Ana Maria Rudge. $-2009$.

$207 \mathrm{f.}$; $30 \mathrm{~cm}$

Tese (Doutorado em Psicologia) - Pontifícia Universidade Católica do Rio de Janeiro, Rio de Janeiro, 2009.

Inclui bibliografia

1. Psicologia - Teses. 2. Psicanálise. 3. Freud, Sigmund. 4. Ferenczi, Sándor. 5. Lacan, Jacques. 6. Trauma. 7. Real. I. Rudge, Ana Maria. II.Pontifícia Universidade Católica do Rio de Janeiro. Departamento de Psicologia. III. Título.

CDD: 150 
Dedico este trabalho a Osmar e Lourdinha, pelo amor e incentivo e ao Pedro, por quem me apaixono todos os dias. 


\section{Agradecimentos}

À minha orientadora Ana Maria, por seu profissionalismo e atenção, assim como pelas muitas contribuições para a realização deste estudo. Quero agradecer, em especial, pelo carinho dispensado para comigo durante todo o período em que precisei me dedicar mais solitariamente ao meu trabalho e tive todo o suporte para continuar produzindo.

Ao CNPq e à PUC-RJ, pelos auxílios concedidos, sem os quais este trabalho não poderia ter sido realizado.

Aos meus pais, pela educação, carinho e orientação de todas as horas.

Ao meu marido, por seu amor e confiança.

Aos meus irmãos, que me ajudaram em diferentes etapas deste trabalho, cada um a seu modo.

Ao amigo Cid, pela presença amiga, principalmente nas horas difíceis.

Aos meus colegas de turma e pesquisa, aos professores e aos funcionários do Programa de Pós-Graduação em Psicologia Clínica que, de uma maneira ou de outra, contribuíram para a realização deste trabalho. 


\section{Resumo}

Favero, Ana Beatriz; Rudge, Ana Maria (Orientadora). A noção de trauma em psicanálise. Rio de Janeiro, 2009. 207p. Tese de Doutorado Departamento de Psicologia Clínica, Pontifícia Universidade Católica do Rio de Janeiro.

Este estudo analisa as contribuições de Sigmund Freud, Sándor Ferenczi e Jacques Lacan sobre o trauma em psicanálise, destacando as principais características de cada abordagem teórica. A concepção de trauma sofre mudanças nas diversas fases da construção teórica freudiana e suas diferentes acepções são discutidas desde a neurotica até a última teoria de angústia (Freud, 1926 [1925]), como também em Moisés e o monoteísmo (Freud, 1939 [1934-1938]). Em Ferenczi, há dois enfoques: no primeiro, os traumas são estruturantes, necessários, inevitáveis ou filogenéticos; no segundo, as situações traumáticas colocam em risco o projeto identificatório do sujeito. Nesta última acepção, o trauma depende de uma falha na relação entre o sujeito e o outro. Valorizando a alteridade na constituição do trauma, Ferenczi se mantém fiel ao que sua clínica lhe revelava: o trauma é fundamentalmente o resultado de uma ação de um outro sobre aquele que é traumatizado. Já em Lacan o trauma é entendido como a entrada do sujeito no mundo simbólico; ele não é um acidente na vida do falante, mas constitutivo da subjetividade. Assim, neste trabalho, é examinado a partir da relação que Lacan estabelece entre as noções de trauma e significante, bem como pela idéia de trauma como encontro com o Real.

\section{Palavras-chave}

Psicanálise; Freud; Ferenczi; Lacan; trauma; Real. 


\section{Abstract}

Favero, Ana Beatriz; Rudge, Ana Maria (Supervisor). The notion of trauma in psychoanalysis. Rio de Janeiro, 2009. 207p. Doctorate thesis Department of Clinical Psychology, Pontifícia Universidade Católica do Rio de Janeiro.

This study analyzes the contributions of Sigmund Freud, Sándor Ferenczi and Jacques Lacan to the concept of trauma in Psychoanalysis, highlighting the main theoretical frameworks in each approach. The concept of trauma has undergone different changes in the various phases of the theoretical Freudian conception, and its diverse meanings have been discussed since the first seduction theory up to the latest theory of anguish (Freud, 1926 [1925]), as well as in Moses and the monotheism (Freud, 1939 [1934-1938]). In Ferenczi, there are two approaches: in the first one, the traumas are of a structuring nature, which means they are either needed, inevitable or philogenetic; in the second one the traumatic situations put the identification project of the subject at risk. In that last approach, the trauma depends on a failure of the relation between the subject and the other. By valuing the alterity in the constitution of trauma, Ferenczi is faithful to what his clinics has revealed: trauma is basically the result of an action of the other upon the one who has been traumatised. In Lacan, on the other hand, the trauma is understood as the entry of the subject into the symbolic world; it is not an accident in the speaking person's life, but rather it is constitutive of their identity. Therefore, trauma in the present study is examined at the light of the relationship established by Lacan between the notions of trauma and signifier, and it also is permeated by the idea of trauma as an encounter with the Real.

\section{Keywords}

Psychoanalysis; Freud; Ferenczi; Lacan; trauma; Real. 


\section{SUMÁRIO}

Introdução

10

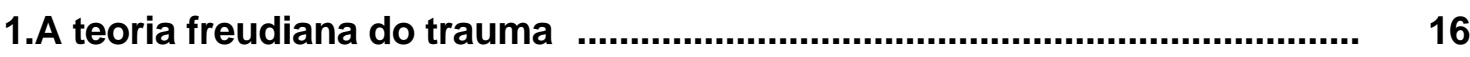

1.10 trauma nas primeiras teorias freudianas .............................................. 16

1.1.1 A 'contravontade' histérica - o conflito psíquico .............................. 20

1.1.2 A definição de trauma na neurotica freudiana .................................. 23

1.20 trauma e a fantasia ......................................................................... 25

1.2.1 O fator infantil na sexualidade ...................................................... 27

1.2.2 As teorias e fantasias sexuais infantis .............................................. 30

1.2.3 As séries complementares e o trauma .......................................... 34

1.3 As neuroses traumáticas e a guerra …...................................................... 36

1.3.1 Sándor Ferenczi: toda neurose de guerra é histeria de angústia ....... 40

1.3.1.1 A revisão da literatura sobre as neuroses traumáticas .......... 43

1.3.2 Karl Abraham e a regressão narcísica ............................................ 45

1.3.3 Ernst Simmel: o supereu nas neuroses de guerra .......................... 48

1.4 A teoria da angústia e o trauma .......................................................... 52

$1.5 \mathrm{O}$ supereu e o trauma .............................................................................. 56

1.6 O período de latência e o efeito do trauma ................................................. 60

1.7 Pontos de contato entre violência, morte e trauma .................................... 62

1.7.1 O trauma infantil ............................................................................. 63

1.7.2 A horda primeva e a questão do parricídio ....................................... 64

1.7.3 A descoberta da pulsão de morte e a violência como trauma ............ 70

1.8 Necessidade e (im)possibilidade de representação do trauma:

a Shoah como paradigma ....................................................................... 74

1.8.1 O rapto de crianças racialmente valiosas ....................................... 77

1.8.1.1 A SS, as Irmãs de Marrom e o projeto Lebensborn .............. 77

1.8.2 O processo de germanização …………...................................... 79

1.8.2.1 Identificação e posterior devolução de crianças raptadas aos genitores: o caso dos gêmeos Marie e Johann .................... $\quad 80$

1.8.3 A culpa carregada pelos filhos do Reich ......................................... 82

1.8.4 Os campos de morte e os testemunhos do irrepresentável .............. 86 
2 A teoria ferencziana do trauma ................................................................ 89

2.1 "Palavras enterradas vivas": o desmentido ............................................... 92

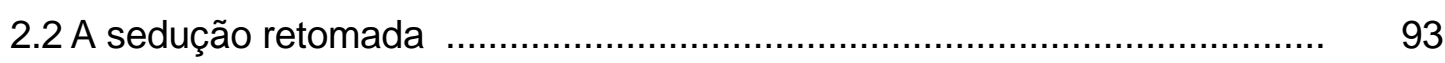

2.2.1 Introjeção: uma comunhão das bocas vazias ................................. 95

2.2.2 A identificação com o agressor ................................................... 98

2.2.3 Fragmentação e clivagem do eu ..................................................... 100

2.2.4 Confissões do Diário ................................................................... 103

$2.3 \mathrm{O}$ estranho do trauma .......................................................................... 106

2.4 Novas bases do trauma: a teoria da sedução generalizada $\ldots \ldots \ldots \ldots \ldots \ldots \ldots . . . . . . . . . . . .108$

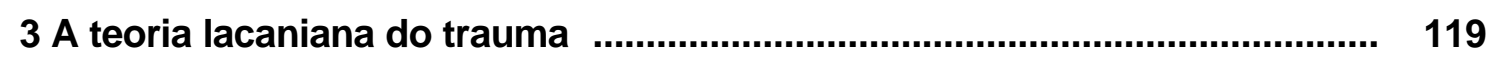

3.1 A clínica do significante e a questão do trauma ....................................... 119

3.1.1 O trauma e o só depois .................................................................. 120

3.1.2 O desejo do Outro como traumático ................................................. 124

3.1.2.1 A separação da mãe é traumática ...................................... 126

3.1.3 Entre o sonho e o despertar: uma realidade faltosa ........................ 127

3.1.4 A compulsão à repetição: uma forma de recordar ............................ 129

3.1.5 O trauma: algo impossível de nomear, e que retorna ...................... 133

3.1.6 Operadores da divisão do sujeito ................................................ 138

3.1.6.1 Indicações millerianas sobre alienação e separação $\ldots . . . . . . . . . .145$

3.1.6.2 Variações do conceito de vel alienante ............................... 147

$3.2 \mathrm{O}$ trauma e o privilégio do Real ............................................................ 154

3.2.1 O estatuto do Real no início do ensino de Lacan:

dos primeiros escritos ao seminário $A$ ética da psicanálise .............. 156

3.2.1.1 A relação do Real com o registro Simbólico ........................ 158

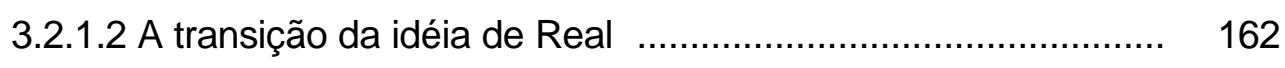

3.2.1.2.1 O Real como pleno ............................................. 162

3.2.1.2.2 O Real é feito de cortes ...................................... 165

3.2.1.2.3 O trauma, o Real e a ética da psicanálise ............. 166

3.2.2 A topologia do nó, o trauma e o Real ............................................ 168

3.2.3 O trauma e a experiência do Real no tratamento psicanalítico .......... 173

Considerações finais 